\title{
Caminhos metodológicos para apreensão de rastros discursivos da mineração ${ }^{1}$
}

Methodological paths to apprehension mining discursive traces

Formas metodológicas para aprovechar rastros discursivos de la minería

DOI: https://doi.org/10.1590/1809-58442021214

Fábia Pereira Lima ${ }^{1}$

https://orcid.org/0000-0001-7802-107X

Isaura Mourão Generoso²

https://orcid.org/0000-0002-9565-5733

Marlene Pereira Machado ${ }^{1}$

https://orcid.org/0000-0001-6028-5907

\section{Marcela Vouguinha ${ }^{3}$}

https://orcid.org/0000-0002-7931-965X

${ }^{1}$ (Universidade Federal de Minas Gerais, Faculdade de Filosofia e Ciências Humanas, Departamento de Comunicação Social. Belo Horizonte - MG, Brasil).

${ }^{2}$ (Universidade Federal de Minas Gerais, Centro de Comunicação. Belo Horizonte - MG, Brasil. Pontifícia Universidade Católica de Minas Gerais, Curso de Comunicação Social, Departamento de Relações Públicas. Belo Horizonte - MG, Brasil).

${ }^{3}$ (Pontifícia Universidade Católica de Minas Gerais, Curso de Comunicação Social, Departamento de Relações Públicas. Belo Horizonte - MG, Brasil).

\section{Resumo}

O presente trabalho pretende apresentar parte do percurso teórico-metodológico adotado para se analisar a constelação discursiva em torno da mineração, segmento econômico marcado por contradições e conflitos, sobretudo após o rompimento de duas barragens de rejeitos de minério de ferro em Minas Gerais (Brasil), que causou a morte de quase trezentas pessoas e sérios danos sociais e ambientais. O trabalho integra a pesquisa "Disputa de sentidos em torno da mineração: marcas

1 Trabalho originalmente apresentado no GP Relações Públicas e Comunicação Organizacional do $42^{\circ}$ Congresso Brasileiro de Ciências da Comunicação, com modificações. 
discursivas das organizações e das instâncias de vigilância civil” (PUC Minas/UFMG), que analisa o discurso e o contradiscurso dos principais atores envolvidos no segmento da mineração, nos níveis global e nacional/local. Abordamos neste trabalho a construção do quadro teórico-metodológico desenvolvido para análise da prática discursiva do International Council on Mining \& Metals ICMM, um dos principais atores internacionais da mineração, tomando como referência a Análise Crítica do Discurso, de Norman Fairclough (2001).

Palavras-chave: Prática Discursiva. Comunicação Organizacional. Mineração. Metodologia. Análise Crítica do Discurso.

\begin{abstract}
The present work intends to present part of the theoretical-methodological path adopted to analyze the discursive constellation around mining, an economic segment marked by contradictions and conflicts, especially after the rupture of two dams of iron ore tailings in Minas Gerais, which caused the death of almost three hundred people and serious social and environmental damage. The work is part of the research "Dispute of meanings in mining: discursive marks of civil surveillance organizations and instances” (PUC Minas/UFMG), which analyzes the discourse and counter discourse of the main actors involved in the mining segment, at the global and national/local levels. In this work we approach the construction of the theoretical-methodological framework developed to analyze the discursive practice of International Council on Mining and Metals - ICMM, one of the main international actors of mining, taking Norman Fairclough's Critical Discourse Analysis as a reference (2001).
\end{abstract}

Keywords: Discursive Practice. Organizational communication. Mining. Methodology. Critical Discourse Analysis.

\title{
Resumen
}

El presente trabajo pretende presentar parte del camino teorico-metodologico adoptado para analizar la constelación discursiva acerca de la minería, un segmento económico marcado por contradicciones y conflictos, especialmente después de la ruptura de dos presas de relaves de mineral de hierro en Minas Gerais, que causaron la muerte de casi trescientos personas y graves daños sociales y ambientales. El trabajo es parte de la investigación "Disputa de significados en minería: marcas discursivas de organizaciones e instancias de vigilancia civil” (PUC Minas/UFMG), que analiza el discurso y el contradiscurso de los principales actores involucrados en el segmento minero, a nivel global y nacional/local. En este trabajo nos acercamos de la construcción del marco teoricometodologico desarrollado para analizar la practica discursiva de Internacional Council on Mining and Metals - ICMM, uno de los principales actores internacionales de minería, tomando como referencia el Análisis Critico del Discurso de Norman Fairclough (2001).

Palabras clave: Práctica Discursiva. Comunicación organizacional. Minería. Metodología. Análisis Crítico del Discurso. 


\section{Introdução}

O estado de Minas Gerais foi palco recente de duas das maiores tragédias socioambientais do Brasil envolvendo o rompimento de barragens de mineradoras. Como consequência, neste momento, nota-se que as contradições e conflitos que acompanham a atividade minerária tornam-se cada vez mais evidentes, como uma das grandes pautas do dia a dia do cidadão comum. A comunidade acadêmica, por sua vez, tem tentado contribuir, a partir da perspectiva dos mais diversos domínios do conhecimento, para ampliar a compreensão sobre o setor, de modo que a sociedade possa qualificar seus argumentos na arena do debate público - inclusive, eventualmente, contradizendo o imperativo do desenvolvimento econômico utilizado de modo recorrente para justificar a prática dos atores que atuam no setor.

É no bojo de tais premissas que pesquisadores da área da Comunicação Social têm se envolvido com o tema, buscando dar voz e visibilidade aos atingidos pelas tragédias e aos que vivem sob o domínio do luto, do risco, da tensão e do medo. Mas como os estudiosos de Comunicação Organizacional têm contribuído (ou podem contribuir) para o debate em torno das lutas (simbólicas e materiais) que se travam em torno da atividade da mineração? Como operacionalizar pesquisas que sobrepujam o viés tecnicista que tradicionalmente marca a trajetória da área e conformam uma prática investigativa que privilegie a rede de relações da qual as organizações fazem parte (e da qual tanto sofre influência quanto influencia)?

Ao formular tais questões, parte-se do pressuposto de que comunicação, também no âmbito das organizações, se configura "como um processo circular que não é determinado pela emissão, mas no qual o sujeito é central nas duas instâncias, reconhecendo como fundamental a ordem da intersubjetividade” (OLIVEIRA; PAULA, 2011, p. 102).

Desse modo, o presente trabalho traz algumas instigações e mostra caminhos teóricometodológicos que tentam dar conta das questões levantadas no escopo da pesquisa "Disputa de sentidos em torno da mineração: marcas discursivas das organizações e das instâncias de vigilância civil” (PUC Minas/UFMG). Ao identificar o discurso dos principais atores que compõem esse setor, nos níveis global e nacional/local, bem como os contradiscursos dos atores sociais envolvidos, a pesquisa tenta lançar luz sobre a constelação discursiva que se dá, atualmente, em torno da mineração e das organizações desse setor, em um jogo de justificação pública cujas causas e consequências, materializadas em textos, tanto podem servir à cristalização quanto à refutação de práticas e estruturas sociais. Afinal, por meio do discurso, é possível compreender "a vida social como uma rede interconectada de práticas² sociais de diversos tipos (econômicas, políticas, culturais, entre outras), todas como um elemento semiótico” (FAIRCLOUGH, 2005, p. 308).

2 Práticas, nessa perspectiva, são as formas de agir na sociedade que podem ser decorrentes de sua estrutura e de uma determinada posição social, mas também de um domínio da ação social e da interação que induz à reprodução ou à transformação de estruturas (FAIRCLOUGH, 2005). 
O principal referencial adotado é a Análise Crítica do Discurso (ACD), ancorada na proposta de Fairclough (2001), em sua concepção tridimensional do discurso. Neste trabalho, apresentamos a abordagem da prática discursiva que envolve um dos principais atores internacionais do setor minerário: o International Council on Mining \& Metals - ICMM ${ }^{3}$, na perspectiva da pesquisa. Ao apresentar a seleção do corpus e os primeiros exercícios analíticos para apreensão dos rastros discursivos sobre a mineração, espera-se evidenciar a relevância no empreendimento de estudos desta natureza não apenas para a área da Comunicação Organizacional, mas, a partir dela, também como esforço que marca o entendimento da comunicação como processo social básico em torno do qual nos entendemos e conformamos como sociedade, em uma construção permanente pelas e nas relações que estabelecemos uns com os outros.

\section{A Análise Crítica do Discurso}

A Análise Crítica de Discurso é considerada por Fairclough (2005, p. 307) “mais como uma teoria do que um método”. Ela envolve uma perspectiva teórica sobre a língua e sobre a semiose, incluindo as diferentes linguagens e formas de construção de sentidos, e propicia "análises linguísticas ou semióticas inseridas em reflexões mais amplas sobre o processo social” (FAIRCLOUGH, 2005, p. 307). Assim, ao estabelecer procedimentos e métodos de pesquisa a partir da ACD, reconhece-se a centralidade da linguagem em uso nos processos de conformação e transformação culturais e sociais (FAIRCLOUGH, 2001). A ACD tem como uma de suas principais fundamentações o trabalho de Foucault, notadamente as obras "A Arqueologia do Saber” e “A Genealogia do Poder”, no que se refere aos principais tópicos:

1. natureza constitutiva do discurso - o discurso constitui o social, como também os objetos e os sujeitos sociais; 2. a primazia da interdiscursividade e da intertextualidade - qualquer prática discursiva é definida por suas relações com outras e recorre a outras de forma complexa; 3 . a natureza discursiva do poder - as práticas e as técnicas do biopoder moderno (por exemplo, o exame e a confissão) são em grau significativo discursivas; 4. a natureza política do discurso - a luta por poder ocorre tanto no discurso quanto subjacente a ele; 5. a natureza discursiva da mudança social - as práticas discursivas em mutação são um elemento importante na mudança social (FAIRCLOUGH, 2001, p. 81-82).

3 A pesquisa que está sendo desenvolvida pelo Grupo de Pesquisa Dialorg, na PUC Minas, deve-se ressaltar, é mais abrangente e investiga diferentes atores em relação na constelação discursiva do setor minerário. No caso deste artigo, toma-se como objeto de análise apenas um desses atores, o ICMM, que também se posiciona como um dos principais porta-vozes do setor. 
Nesse sentido, o discurso é tanto uma forma de agir no mundo e sobre os outros como um modo de representação e significação. O discurso é tanto modulado como modula, é tanto restringido como pode restringir a estrutura social, podendo tanto reforçar determinadas práticas (e estruturas) como transformá-las. Ainda, é o momento "integrante e irredutível das práticas sociais que envolve a semiose/linguagem em articulação com os demais momentos das práticas: fenômeno mental, relações sociais e mundo material” (RAMALHO; RESENDE, 2011, p. 16).

Para evidenciar as dimensões do discurso, Fairclough (2001) propõe uma concepção tridimensional em que a prática textual está contida na prática discursiva e, essa, na prática social, conforme representado a seguir"

Figura 1 - Concepção tridimensional do discurso

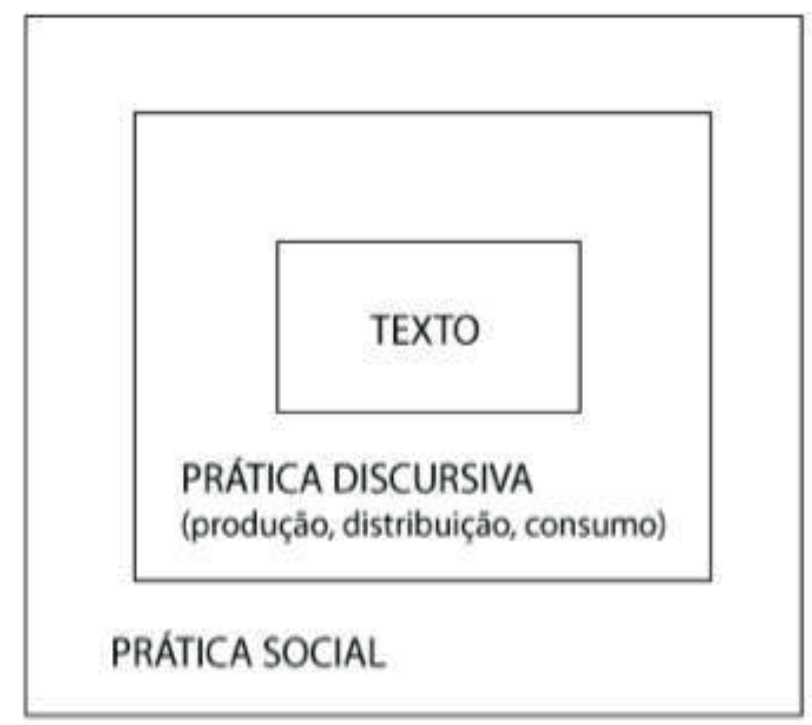

Fonte: Fairclough (2001, p. 101).

\footnotetext{
4 O trabalho reconhece e considera reflexões posteriormente feitas à proposição seminal da ACD aqui assumida, incluindo discussões empreendidas pelo próprio autor, ver: Chouliaraki e Fairclough (1999), Fairclough (2009) ou o trabalho de Ramalho e Resende (2004). Igualmente, toma o modelo adotado como uma das referências em ACD, que precisa ser considerada no bojo de outras proposições que buscam articular a dimensão da agência e estrutura, conforme o amplo espectro de operacionalização no campo linguístico (WOCK; MEYER, 2009). Porém, entendemos que a síntese metodológica inicialmente proposta, em sua essência, resta preservada e, por isso, é desta forma considerada no trabalho apresentado.
} 
Na ACD, a análise textual considera aspectos como "controle interacional”, “coesão”, “polidez”, “ethos”, "gramática”, “transitividade”, “modalidade”, “significado das palavras”, “criação de palavras” e "metáforas”. A análise da prática discursiva enfoca aspectos relacionados aos processos de produção representada pela "intertextualidade manifesta” e pela "interdiscursividade", circulação e recepção dos textos manifestados pelas “cadeias intertextuais” e pelo consumo das informações representado pela "coerência” (FAIRCLOUGH, 2001), conforme será detalhado no item a seguir.

E a dimensão da prática social volta-se para análises das “ordens do discurso”, compreendidas como "estruturação social da diferença semiótica, uma ordenação social particular das relações entre os vários modos de construir sentido” (FAIRCLOUGH, 2005, p. 310), e dos "efeitos ideológicos e políticos" do discurso, visando a entender como se dá a construção e a disputa de sentidos e significados, que possibilitam a manutenção e/ ou a transformação da realidade social. "Nas práticas sociais, a linguagem se manifesta como discurso: como uma parte irredutível das maneiras como agimos e interagimos, representamos e identificamos a nós mesmos, aos outros e a aspectos do mundo por meio da linguagem” (RAMALHO; RESENDE, 2011, p. 15).

Assim, o objetivo central de nossos estudos tem sido o de construir uma proposta metodológica para pesquisas em comunicação organizacional inspirada na ACD, buscando compreender as complexas dinâmicas da formação e movimentação de públicos, bem como suas interinfluências nos contextos de controvérsia e de debate público. Como defendem Ramalho e Resende (2004, p. 201), uma das funções da ACD é tentar desvelar como aspectos negativos e socialmente naturalizados, sobretudo no contexto da economia neoliberal, “podem ser mudados pela agência humana (...), mas são, pelo menos em parte, o resultado de estratégias particulares engendradas por meio de decisões políticas de acordo com interesses determinados”.

A análise crítica de discurso é uma abordagem metodológica que privilegia o papel constitutivo do discurso na sociedade contemporânea. Embora sua origem seja nos estudos da linguagem (FAIRCLOUGH, 2001), a articulação que propõe entre discurso e outras práticas sociais, sem reduzir tudo ao discurso, tem sido um aporte valioso para os estudos críticos de comunicação organizacional que se preocupam em examinar as relações de poder entre discursos e atores (OLIVEIRA; HENRIQUES; LIMA, 2019, p. 7-8).

Desse modo, foi elaborado o seguinte diagrama para ilustrar o modelo analítico elaborado para essa pesquisa, a partir das dimensões do discurso propostas por Fairclough (2001): 
Figura 2 - Dimensões analíticas do discurso

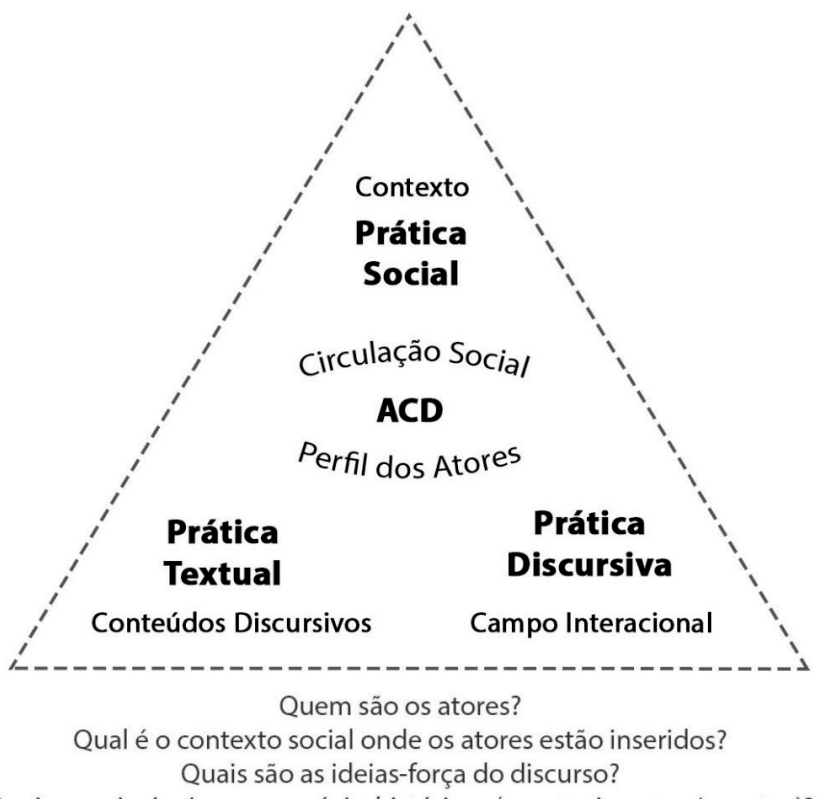

Quais os principais marcos sócio-históricos (acontecimentos/eventos)?

Como estes atores definem para sí um campo interacional (com quem se relacionam)?

Quais são os principais apelos retóricos contidos nos posicionamentos/proferimentos?

Por onde se dá a circulação de seus discursos (meios, canais, veículos)?

Quais são as principais controvérsias nas quais eles estão imersos?

Quais são as denúncias contidas nestes textos?

Fonte: Elaborado pelas autoras, a partir de Fairclough (2001).

Para efeito dos objetivos do presente artigo, apresentaremos a seguir os modos pelos quais a prática discursiva tem sido trabalhada na pesquisa.

\section{A prática discursiva}

A prática discursiva, fundamentada em Fairclough (2001), traz elementos foucaultianos em sua lógica ao mesmo tempo em que faz a crítica ao raciocínio desse autor. Para Foucault (2012), a prática discursiva não se limita a um discurso ou ao modo de fabricação de, mas constitui regras que definem as condições de exercício da função enunciativa e, de forma complexa, está sempre em relações e recorrendo a outras práticas discursivas e não-discursivas, não se restringindo a um texto ou a um discurso específico. Esse é um dos principais pontos que marca a diferença entre as noções de prática discursiva adotadas pelos dois autores: para Fairclough (2001, p. 82), a prática discursiva é um dos elementos tridimensionais do discurso - ela está dentro da prática social e contém o texto, 
mas deve ser compreendida a partir de "exemplos reais das pessoas que fazem, dizem ou escrevem coisas”. Nesse sentido, é necessário que a ACD, sobretudo na dimensão da prática discursiva, seja desenvolvida a partir do texto e da linguística, ou seja, das "instâncias concretas de discurso", pois,

Quando elas [as instâncias concretas de discurso] são incluídas na ADTO [Análise do Discurso Textualmente Orientada], elas seriam sujeitas não apenas às formas linguísticas de análise textual, mas à análise em três dimensões: análise do texto, análise dos processos discursivos de produção e interpretação textual (incluindo a questão de quais tipos e gêneros de discurso são tornados e como eles são articulados) e análise social do evento discursivo, em termos de suas condições e efeitos sociais em vários níveis (situacional, institutional, societário). [...]. Assim, o que eu defendo é a análise textual em conjunção com outros tipos de análise. (FAIRCLOUGH, 2001, p. 82).

Sendo assim, assumimos, em nossa pesquisa, a ACD a partir de Fairclough (2001) e, nessa lógica, consideramos o discurso ${ }^{5}$ da mineração como prática discursiva que não se opõe à prática social ${ }^{6}$, mas se manifesta como uma forma especial dessa, moldada de maneira consciente e inconsciente por estruturas sociais, por relações de poder e pela natureza da prática social na qual está envolvido.

Nessa perspectiva, quando tratamos da prática discursiva da mineração, estamos nos referindo à manifestação do discurso na forma de textos, sendo esses falados e/ou escritos, e considerando os processos de produção, de distribuição e de consumo textual, sempre em relações com outros textos (intertextualidade e interdiscursividade) e com a prática social. Para tanto, é necessário proceder ao que Fairclough (2001) denomina macroanálise e identificar os processos e as ordens discursivas utilizadas para a produção e para a interpretação dos textos.

O discurso, compreendido como aquele que constitui e constrói o mundo em significado - no caso do presente artigo, “o mundo da mineração” - deve ser observado a partir de três aspectos constitutivos e correlacionados a três funções da linguagem e a dimensões de sentido que coexistem e interagem em todo discurso (FAIRCLOUGH, 2001): função identitária, função relacional e função ideacional. O primeiro aspecto coloca o discurso como identidade e posição de sujeitos e está correlacionado à linguagem identitária ou a como esses sujeitos se estabelecem por meio do discurso. Já o segundo refere-se à forma como um determinado discurso contribui para as relações sociais entre organizações e entre pessoas,

5 Para Fairclough (2001, p. 91), o discurso deve ser percebido como “uma prática, não apenas de representação de mundo, mas de significação do mundo, constituindo e construindo o mundo em significado”.

6 Importante ressaltar que, também em Fairclough (2001, p. 93), a análise da prática discursiva, ainda que realizada a partir do texto, deve estar sempre relacionada à da prática social, posto que "a constituição discursiva da sociedade não emana de um livre jogo de ideias nas cabeças das pessoas, mas de uma prática social que está firmemente enraizada em estruturas sociais materiais, concretas, orientando-se para elas". 
quando exerce a função relacional, estabelecendo as formas como as relações sociais são representadas e negociadas entre os participantes do discurso. E, por fim, o terceiro aspecto diz respeito à contribuição do discurso para a construção de sistemas de conhecimento e de crenças, quando exerce a função ideacional da linguagem, ou seja, os textos passam a significar o mundo e seus processos. Assim, a prática discursiva "contribui para reproduzir a sociedade (identidades sociais, relações sociais, sistemas de conhecimento e crença) como é, mas também contribui para transformá-la” (FAIRCLOUGH, 2001, p. 92).

Identificados esses aspectos, partimos para a análise da prática discursiva, considerando quatro passos: a) a interdiscursividade, b) a intertextualidade manifesta, c) as cadeias textuais e d) a coerência dessa prática ou, dito de outro modo, o sentido, do ponto de vista do leitor. A interdiscursividade, que está na produção do discurso, remete à origem desse e contém os elementos que vão dar ordem ao discurso, que conduzem e conformam o gênero. Na análise da interdiscursividade, é preciso verificar se o texto e as interações ${ }^{7}$ nele presentes contêm elementos que podem denotar a rearticulação da ordem discursiva.

Nessa perspectiva, ao analisarmos a interdiscursividade da mineração a partir dos posicionamentos do ICMM, buscamos compreender a ordem do discurso e sua relação com o contexto: a indústria da mineração, a mídia - em particular, na nossa análise - e a sociedade. "Um aspecto dessa ordenação é a dominância: algumas maneiras de construir sentido são dominantes ou estão em voga para certas ordens de discurso; outras são marginais, subversivas, alternativas” (FAIRCLOUGH, 2001, p. 92). Torna-se fundamental, dessa forma, identificar gêneros, discursos e estilos que constituem o texto e a maneira como geram articulações particulares.

A intertextualidade manifesta, ou seja, a referência explícita a outros textos dentro daqueles que estamos analisando, é mais um elemento que deve ser observado, pois também funciona como indicativo que remete à origem dessa prática discursiva. Já a análise das cadeias intertextuais busca compreender a distribuição da prática discursiva, a variedade de domínios institucionais, a potencialidade de utilização e reutilização do discurso para além dos ouvintes/leitores aos quais se dirige. Nesse sentido, o discurso da mineração, sobretudo o realizado pelo ICMM, produz textos

de forma a antecipar sua distribuição, transformação e consumo, e neles constroem leitores múltiplos. Podem antecipar não apenas os 'receptores' (aqueles a quern o texto se dirige diretamente), mas também os 'ouvintes' (aqueles a quern o texto não se dirige diretamente, mas são incluídos entre os leitores) e 'destinatários' (aqueles que não constituem parte dos leitores 'oficiais', mas são conhecidos como consumidores de fato) (FAIRCLOUGH, 2001, p. 108).

7 Fairclough (2005) assume o termo interação em seu sentido mais amplo, considerando tanto a conversa como um artigo de jornal, por exemplo, como formas de interação, ainda que os interlocutores não estejam nos mesmeos tempo e espaço. Nessa perspectiva, o texto escrito, disposto no site do ICMM, é uma forma de interação. 
Assim, tais discursos consideram sua distribuição a leitores múltiplos, com vistas a multiplicar sua reverberação. Nessa lógica, seguimos com a análise da prática discursiva para compreender a coerência do discurso, cuja observação não se restringe à produção, mas encontra-se, sobretudo, relacionada ao consumo do texto. Interessa ressaltar a importância da semiose na conformação de estilos diversos e sua relação com as diferentes posições ocupadas pelos atores sociais na prática discursiva. Cada posição está relacionada a aspectos de identidade que excedem a própria construção da posição. Segundo afirma Fairclough (2005, p. 310), “Os estilos são maneiras de ser, identidades, em seu aspecto semiótico”.

Fairclough (2001) também chama a atenção para a relação entre a prática discursiva e a prática social, posto que as conexões de sentido geralmente apoiam-se em pressupostos contextuais, sociais e ideológicos, e, assim, a leitura coerente está relacionada aos princípios interpretativos particulares aos quais o leitor recorre. No entanto, isso não significa, conforme ressalta o autor (FAIRCLOUGH, 2001, p. 114), a inexistência de possibilidade "de luta quanto a diferentes leituras dos textos, mas também de resistência às posições estabelecidas nos textos". A seguir, com vistas a compreender a importância do ator social cujo discurso é objeto de análise, situam-se o ICMM e seu lugar no setor minerário.

\section{ICMM nasce com o discurso da mudança}

O International Council on Mining and Metals (Conselho Internacional de Mineração e Metais - ICMM) nasceu em 2001, após um período prolongado de recessão econômica, desde a década de 1980 até o final da de 1990, alimentada por crises do petróleo e pelo colapso da União Soviética, entre outros fatores que impactaram na demanda global por minerais. No final dos anos de 1990, os investidores haviam perdido, em grande parte, o interesse pela mineração e os preços das commodities despecaram. A preocupação global da época curvou-se ao desenvolvimento tecnológico e os produtos tornaram-se menos intensivos em materiais. Os tubos de cobre, por exemplo, passaram a ser produzidos de maneira mais fina, reduzindo a quantidade de minério necessário (HUMPHREYS, 2015).

Associavam-se a esse cenário, as críticas sociais e a oposição pública ao setor no início dos anos 2000, comprometendo a 'licença social para operar’8 da indústria da mineração. Diante disso, um grupo de líderes e executivos de empresas de mineração e metais criou a Global Mining Initiative (GMI). Liderada pelo Conselho Empresarial Mundial para o Desenvolvimento Sustentável (WBCSD), a GMI "buscava uma reforma interna, uma revisão das várias associações às quais elas pertenciam e um estudo rigoroso das questões sociais que sua indústria tinha que enfrentar” (ICMM, 2021).

A iniciativa propiciou um processo de consulta e pesquisa, considerado inédito no setor, que se estendeu por dois anos, reunindo e trabalhando percepções de diferentes atores

8 Licença social para operar: a aprovação ou aceitação contínua das atividades de uma empresa pela comunidade local e outras partes interessadas. Esse endosso informal pode ser obtido e renovado por meio de um diálogo significativo e comportamento responsável (ICMM, 2021). 
sociais interessados e envolvidos com o setor. Apresentado como relatório, o resultado dessa iniciativa "propôs uma agenda de mudanças que revitalizaria a indústria e traria um maior alinhamento entre as ações da indústria e os valores da sociedade contemporânea exatamente onde uma lacuna significativa se abriu” (ICMM, 2021).

Assim nasceu o ICMM, com o objetivo de se configurar como um catalisador das mudanças para a indústria de mineração e metais. Nessa lógica, em 2003, o ICMM “desenvolveu 10 princípios definidores para orientar a mudança na indústria. Ao longo dos anos, uma série de declarações de posicionamento foi desenvolvida para acompanhar e fortalecer os 10 Princípios do ICMM” (ICMM, 2021). Hoje, o Conselho se apresenta como organização internacional que "apoia uma indústria da mineração segura, justa e sustentável” e congrega 27 das maiores empresas globais de mineração e metais, e mais de 30 associações regionais e de mercado, em todo o mundo.

\section{Rastros Discursivos da Mineração}

Conforme Oliveira et al. (2019, p. 10), "há um metadiscurso ${ }^{9}$ produzido e sustentado pela indústria da mineração, em nível global, que é uma base importante para as justificações públicas deste setor econômico”. Nesse contexto, definimos enquanto objeto de análise o discurso da mineração, nucleado pelo ICMM. Esse ator foi selecionado por sua representatividade, na medida em que ocupa lugar de destaque na elaboração e circulação de um pensamento sobre a mineração, conforme apresentado. A delimitação do corpus norteiase por informações publicadas pelo próprio ator/enunciador (ICMM) e/ou informações publicadas sobre ele. A pesquisa se baseia em pautas envolvendo o ICMM e se desenvolve a partir da procura sistemática em motores de busca ${ }^{10}$ na internet, com filtros e palavras-chave.

As empresas membros do ICMM, às quais podemos considerar as receptoras, leitoras diretas de seu discurso, se comprometem com um conjunto de 10 princípios da instituição e uma série de declarações de posição desenvolvidas para estender esses princípios e alinhálos como melhores práticas para o desenvolvimento sustentável da indústria de minerais e metais (ICMM, 2019). Como guia para esse alinhamento, atualmente estão disponíveis no site do ICMM oito Declarações de Posições, datadas de setembro de 2003, fevereiro de 2009, julho de 2009, janeiro de 2010, junho de 2011, maio de 2013, dezembro de 2016, e janeiro de 2017. Considerando o objetivo da nossa pesquisa, valemo-nos dessas Declarações de Posição como pautas proeminentes do ator para embasar as buscas interacionais e a composição de um mapa relacional.

9 Metadiscurso é um campo "de estudo da linguagem a partir de diferentes perspectivas teóricas e pode ser considerado como uma corporificação das relações de interação entre interlocutores através do texto. \{...\} é, portanto, um elo importante entre um texto e seu conteúdo, uma vez que aponta para as expectativas que os leitores têm por certas formas de interação e engajamento” (SILVA, 2017, p. 41).

10 Google e Duck Duck GO. 
A partir da leitura completa das sete Declarações de Posições que se enquadram no recorte temporal da pesquisa (2008 a 2018), realizamos a análise da prática discursiva em suas quatro dimensões: a interdiscursividade, a intertextualidade manifesta, as cadeias intertextuais e a coerência do texto. Buscamos identificar, nesses documentos, o que nos permitiu definir as palavras-chave que utilizamos nos motores de busca da internet, Duck Duck GO e Google. Em ambos, as palavras foram pesquisadas com a aplicação do filtro “notícias” dos próprios buscadores, uma vez que nosso objetivo é analisar a constelação discursiva em torno da mineração e não apenas o discurso de um ator específico. Também utilizamos nas buscas os idiomas português, inglês e espanhol. Optamos pela página de navegação anônima ${ }^{11}$ na tentativa de minimizar os resultados embasados por algoritmos pessoais de busca.

Na formação do corpus, não foram contabilizados os resultados de notícias que ultrapassaram o recorte temporal de 10 anos (2008 a 2018); notícias disponíveis apenas para assinantes pagos; os links que deram erro ao serem clicados; e, obviamente, as notícias que, apesar de aparecerem no filtro de busca de determinada palavra-chave, não abordam a temática da pesquisa em questão. Ainda no processo de delimitação e conformação do corpus, os resultados encontrados nos buscadores podem se entrecruzar em três situações, sendo igualmente excluídos: aparição em mais de uma palavra-chave; aparição na mesma palavra-chave em outro buscador; aparição em outra palavra-chave em outro buscador.

Para a análise piloto, nessa fase exploratória, definimos de maneira aleatória a Declaração de Posição de junho de 2011, intitulada "Princípios para projetar políticas sobre mudança do clima”, como amostra experimental do percurso metodológico aqui proposto. Considerando os quatro passos apresentados anteriormente, analisamos a interdiscursividade, a intertextualidade manifesta, a coerência e as cadeias intertextuais nesse material, bem como as funções identitária, ideacional e relacional do discurso. Nesta análise, que ultrapassa os objetivos do presente trabalho, traçamos o perfil do ator (ICMM) e, como resultado, elegemos as seguintes palavras-chave para busca nos buscadores Duck Duck GO e Google: Efeito estufa ICMM; Greenhouse effect ICMM; Efecto invernadero ICMM; Desenvolvimento sustentável ICMM; Sustainable development ICMM; Desenvolvimiento sustentable ICMM; Mudança de clima ICMM; Climate change ICMM; Cambio de clima ICMM.

Como resultado desse esforço inicial, chegamos a um corpus composto por 157 documentos disponíveis e que não se repetem, nos dois buscadores (34 documentos no Duck Duck Go e 123, no Google), conforme mostra a tabela a seguir:

11 Recurso disponibilizado por alguns navegadores contemporâneos, o modo anônimo de navegação impede a gravação das informações recebidas no navegador por meio da rede mundial de computadores. 
Tabela 1 - Conformação do corpus gerado a partir dos Princípios para projetar políticas sobre mudança do clima

\begin{tabular}{|c|c|c|c|c|c|}
\hline Palavra-chave DUCK DUCK GO & Resultado ( $\mathrm{n}=$ ) & Eliminações ( $\mathrm{n}-$ ) & Causas da Eliminação & Corpus & \\
\hline Efeito estufa ICMM & $\begin{array}{c}0 \\
\end{array}$ & & & 0 & \\
\hline Greenhouse effect ICMM & 3 & & & 3 & \\
\hline Efecto invernadero ICMM & 0 & & & 0 & \\
\hline Desenvolvimento sustentável ICMM & 0 & & & 0 & \\
\hline Sustainable development ICMM & 29 & 12 & Tempo (9) Pago (3) & 17 & \\
\hline Desenvolvimiento sustentable ICMM & 0 & & & 0 & \\
\hline Mudança de clima ICMM & 16 & 16 & \begin{tabular}{|l} 
Pago (1) Tema (15) \\
\end{tabular} & 0 & \\
\hline Climate change ICMM & 27 & 8 & Tempo (4) Tema (2) Pago (2) & 14 & REPETIDOS 5 \\
\hline \multirow[t]{2}{*}{ Cambio de clima ICMM } & 26 & 26 & \begin{tabular}{|l} 
Tempo (15) Tema (11) \\
\end{tabular} & 0 & \\
\hline & 101 & & & 34 & \\
\hline Palavra-chave GOOGLE & Resultado ( $\mathrm{n}$ ㅇ) & Eliminações $(\mathrm{n} \cong$ ) & Causas da Eliminação & Corpus & \\
\hline Efeito estufa ICMM & \begin{tabular}{|c|}
0 \\
\end{tabular} & - & - & - & \\
\hline Greenhouse effect ICMM & 13 & 1 & Pago (1) & 10 & REPETIDOS 2 \\
\hline Efecto invernadero ICMM & 2 & 1 & Tema (1) & & REPETIDO 1 \\
\hline Desenvolvimento sustentável ICMM & 1 & 1 & Pago (1) & 0 & \\
\hline Sustainable development ICMM & 141 & 30 & Tema (28) Erro (2) & 97 & REPETIDOS 14 \\
\hline Desenvolvimiento sustentable ICMM & 5 & 3 & Tema (3) & 2 & \\
\hline Mudança de clima ICMM & 15 & 12 & Tema (11) Erro (1) & 3 & \\
\hline Climate change ICMM & 56 & 13 & Tema (9) Pago (3) Erro (1) & 11 & REPETIDOS 32 \\
\hline \multirow[t]{2}{*}{ Cambio de clima ICMM } & 7 & 4 & Tema (3) Erro (1) & & REPETIDOS 3 \\
\hline & 240 & & & 123 & \\
\hline
\end{tabular}

Fonte: As autoras (2019).

A partir das palavras-chaves pesquisadas percebemos que 'desenvolvimento sustentável' e 'mudança de clima' são as pautas que mais reverberam entre as notícias dos buscadores, evidenciando um rastro discursivo em torno da mineração que pode ser considerado, apropriando-nos de Fairclough (2005, p. 314), como uma tentativa de “rearrumação de práticas sociais”, o que será configurado, em etapa posterior da pesquisa, em ideias-força na análise da dimensão textual.

Nesse sentido, e a partir dessa Declaração de Posição, em relação aos três aspectos constitutivos e correlacionados às funções da linguagem e dimensões de sentido que coexistem e interagem em todo discurso, podemos dizer que o ICMM identifica-se como a voz da mineração ao mesmo tempo em que se coloca como o interlocutor do setor. Pretende, por meio de um processo semiótico, reestruturar e reescalonar as ordens do discurso, "envolvendo novas relações estruturais e escalares entre os gêneros, discursos e estilos” (FAIRCLOUGH, 2005, p. 315). O ICMM e seus membros colocam-se como detentores de "uma plataforma legítima a partir da qual a indústria da mineração pode promover os princípios e tornar-se parte do processo de projeção de políticas” (ICMM, 2019), reforçando o seu papel na estrutura do setor e, consequentemente, na sociedade. Como função ideacional, o ICMM, sempre em conjunto com seus membros, busca "contribuir para o desenvolvimento sustentável enquanto mantêm-se competitivos em uma economia baixa em carbono”, potencializando, com esse estilo, sua representação de dominância.

Em relação à interdiscursividade, podemos dizer que o discurso do ICMM, na posição de declaração analisada, assume o gênero de ordem, uma vez que coloca a obrigatoriedade de implementação dessa por parte de seus membros, inclusive com a determinação de prazos para 
tanto. A noção de desenvolvimento sustentável nessa declaração de posição está associada à competitividade contínua das empresas e devem envolver governos, indústria, sociedade civil e mídia, elementos que conferem ordem ao discurso e reforçam relações estruturais já estabelecidas no domínio social. Quando buscamos analisar a intertextualidade manifesta, o ICMM faz referências a outros órgãos/instituições como UNFCC (Copenhagen, 2009), a Organização Mundial do Comércio (OMC) e a UNCSD Rio+20 no sentido de fortalecer seu discurso e, consequentemente, a prática discursiva da mineração.

Do ponto de vista dos principais veículos que reverberam as pautas selecionadas e, assim, conformam o campo interacional, a pesquisa online os revelou na seguinte ordem de relevância: 1) Mining Review: principal revista mensal e plataforma digital na indústria de mineração africana; 2) Mining Global: publicação digital para executivos sobre o setor; 3) Unesco/WHC: plataforma com informações que são criadas por variadas fontes internas e externas ao Centro do Patrimônio Mundial da Unesco. A partir desses primeiros achados, investiremos no aprofundamento não apenas sobre a identificação desses atores, entendidos no âmbito da constelação discursiva da mineração, como também dos principais interlocutores que aparecem de algum modo acionados nos documentos analisados.

\section{Considerações finais}

Tratamos, no presente artigo, dos passos a serem desenvolvidos para a análise da prática discursiva a partir de Fairclough (2001) e apresentamos o percurso inicial para a realização da pesquisa proposta, que se configuram como os primeiros ensaios para uma pesquisa utilizando esses procedimentos. Nessa análise piloto, já conseguimos perceber o papel do ator ICMM na divulgação e reverberação do “discurso da mineração” em relação às políticas sobre mudança do clima, colocando-se numa posição privilegiada de representação e de consolidação dessa prática discursiva, sempre em conjunto com seus membros, as 27 empresas de mineração e metais e as 30 associadas, consideradas membros/parte do ICMM.

Conforme destacamos na análise apresentada, foi possível identificar a complexidade e extensão desse discurso, em sua reverberação na mídia. Nos primeiros achados, já conseguimos identificar ideias-forças relevantes, alguns dos principais interlocutores e como esses se interrelacionam discursivamente. Percebemos ainda a força de organizações como o ICMM na reverberação da prática discursiva da mineração definindo um modo de pensar e de ser da sociedade em um jogo de justificação pública do setor de forma a cristalizá-la como prática social - e econômica - necessária.

Assim, podemos dizer que essa análise piloto, apresentada como um possível caminho metodológico para a apreensão de discursos organizacionais, abre perspectivas promissoras para a pesquisa no contexto da mineração e de outros setores e organizações, a partir da ACD. Por meio dela, é possível identificar como o poder das organizações, no caso do setor minerário, pode ser reforçado e reverberado a partir do discurso que produz conhecimento, fazendo circular informações consumidas como discursos naturalizados, portadores 
de verdades, e como formas de agir e de interagir, moldando e naturalizando crenças e comportamentos. No entanto, configuram-se como discursos operados pelas organizações, incluindo as áreas de comunicação, que representam a dominância do setor apresentado como imprescindível à economia global e nacional/local. Nesse sentido, a análise mostra que o discurso proposto a partir do ICMM como discurso de mudança, limita-se a ajustes e adpatações com vistas a proporcionar a melhor convivência com a sociedade.

Nesse sentido, a análise dos discursos organizacionais amparada na ACD apresenta potencial para repensar a própria atuação da comunicação em contextos organizacionais para além do viés utilitário e tecnicista que marcam a trajetória da área, conforme mencionamos logo na introdução deste artigo. A Análise Crítica de Discurso nos mostra que os gêneros, os discuros e os estilos de um setor como o minerário têm capacidade para colonizar governos e setores públicos em diferentes escalas, mesclando e combinando formas antigas e novas evidenciadas no discurso, por meio de maneiras dominantes de construir sentidos com vistas a manter e fortalecer posição de dominância. Se Rajagopalan (2003) reivindica ao linguista um papel de cientista social que deve servir à sociedade, contribuindo para a melhoria das condições de vida dos setores menos privilegiados, também praticantes na área da comunicação organizacional devem ser chamados ao reconhecimento de suas responsabilidades na conformação do mundo social (e das desigualdades que o atravessam), a partir das práticas discursivas que conformam.

\section{Referências}

CHOULIARAKI, L.; FAIRCLOUGH, N. Discourse in late modernity: rethinking critical discourse analysis. Edinburgh: Edinburgh University Press, 1999.

FAIRCLOUGH, N. A dialectical-relational approach to critical discourse analysis in social research. In: WOCK, R.; MEYER, M. (ed). Methods of Critical Discourse Analysis. 2a. ed. Londres: SAGE, 2009, p. 162-186.

FAIRCLOUGH, N. Discurso e mudança social. Brasília: Editora Universidade de Brasília. 2001. 316p.

FOUCAULT, M. A Arqueologia do Saber. 8a. ed. Rio de Janeiro: Forense Universitária. 2012. 254p.

HUMPHREYS, D. The remaking of the mining industry. Basingstoke: Palgrave Macmillan, 2015. 256p.

INTERNATIONAL COUNCIL ON MINING AND METALS. Compromissos dos membros. Londres: ICMM, 2019. Disponível em: https://www.icmm.com/pt/nossos-membros/compromissos-dos-membros/ declaracoes-de-posicao. Acesso em: 20 jun. 2019.

INTERNATIONAL COUNCIL ON MINING AND METALS. Our history. Londres: ICMM, 2021. Disponível em: https://www.icmm.com/en-gb/about-us/annual-reviews/our-history. Acesso em: 4 jan. 2021.

OLIVEIRA, I. de L; PAULA, C. F. C. Comunicação no contexto das organizações; produtora ou ordenadora de sentidos? In: OLIVEIRA, I. de L.; SOARES, A. T. Interfaces e tendências da comunicação no contexto das organizações. São Caetano do Sul: Difusão Editora, 2011. p. 91-108.

OLIVEIRA, I. de L.; HENRIQUES, M. S.; LIMA, F. P. Um modelo analítico das práticas discursivas no contexto das organizações: proposta metodológica em construção. In: ENCONTRO ANUAL DA COMPÓS. 
Porto Alegre: COMPÓS, 2019. Anais.... Disponível em: http://www.compos.org.br/biblioteca/trabalhos_ arquivo_AQNHMN8LJY4B5043FCE9_28_7433_21_02_2019_23_20_42.pdf. Acesso em: 4 jan. 2021.

RAJAGOPALAN, K. Por uma lingüística crítica. São Paulo: Parábola, 2003.

RAMALHO, V.; RESENDE, V. de M. Análise de Discurso Crítica, do modelo tridimensional à articulação entre práticas: implicações teórico-metodológicas. Linguagem em (Dis)curso - LemD, Tubarão, v. 5, n.1, p. 185-207, jul./dez. 2004.

RAMALHO, V.; RESENDE, V. de M. Análise de discurso (para a) crítica: O texto como material de pesquisa. Coleção: Linguagem e Sociedade, v. 1, Campinas, SP: Pontes Editores, 2011.

SILVA, A. Metadiscurso na perspectiva de Hyland: definições, modelos de categorização e possíveis contribuições. Letras, Santa Maria, v. 27, n. 54, jan./jun., 2017. p. 41-67.

WOCK, R.; MEYER, M. (ed). Methods of Critical Discourse Analysis. 2a. ed. Londres: SAGE, 2009.

\section{Fábia Pereira Lima}

Professora Adjunta do Departamento de Comunicação Social e pesquisadora colaboradora do Programa de Pós-Graduação em Comunicação Social da Universidade Federal de Minas Gerais (UFMG). Diretora do Centro de Comunicação da UFMG. Graduada em Relações Públicas, especialista em Gestão Estratégica de Marketing, mestre em Comunicação Social (PUC Minas). Integrante dos Grupos de Pesquisa Comunicação, Mobilização Social e Opinião Pública - MOBILIZA (UFMG) e DIALORG - Comunicação no Contexto Organizacional: aspectos teórico-conceituais (PUCMG). Vice-Presidente da Associação Brasileira de Pesquisadores de Comunicação Organizacional e Relações Públicas (ABRAPCORP). Coordenadora do Intercom Júnior de Relações Públicas e Comunicação Organizacional. Tem experiência e trabalhos publicados na área de Comunicação Social, com ênfase em Relações Públicas, nos seguintes temas: comunicação organizacional, planejamento da comunicação, comunicação estratégica, relações públicas e discurso organizacional. E-mail: fabialima@gmail.com.

\section{Isaura Mourão Generoso}

Coordenadora do Núcleo de Assessoria de Imprensa do Centro de Comunicação da UFMG e professora do Curso de Comunicação Social da PUC Minas. Graduada em Jornalismo (UFMG), especialista em Comunicação e Gestão Empresarial (PUC Minas) e doutora em Comunicação e Informação pela Universidade Federal do Rio Grande do Sul (UFRGS). Integrante dos Grupos de Pesquisa DIALORG - Comunicação no Contexto Organizacional: aspectos teórico-conceituais (PUC Minas) e GCCOP - Grupo de Pesquisa em Comunicação Organizacional, Cultura e Relações de Poder. Coordenadora do Grupo de Pesquisa em Comunicação Organizacional e Relações Públicas da Intercom. Tem experiência e trabalhos publicados na área de Comunicação Organizacional. E-mail: mouraoisaura@gmail.com. 


\section{Marlene Pereira Machado}

Doutoranda em Comunicação pela Universidade Federal de Minas Gerais - UFMG (Bolsista Capes/Proex), mestre em Comunicação pela PUC Minas, jornalista, com MBA em Gestão, pela Fundação Dom Cabral, e especialista em Gestão da Comunicação, pela PUC Minas. Integrante dos grupos de pesquisa MOBILIZA: Comunicação, Mobilização Social e Opinião Pública (UFMG) e DIALORG: Comunicação no Contexto Organizacional: aspectos teórico-conceituais (PUC Minas). Atuação e trabalhos publicados na área de Comunicação Organizacional. E-mail: 2016marlenemachado@gmail.com.

\section{Marcela Vouguinha Cunha}

Mestra em Comunicação Social pela Pontifícia Universidade Católica de Minas Gerais. Graduada em Relações Públicas (PUC Minas). Integrante do grupo de pesquisa DIALORG - Comunicação no Contexto Organizacional aspectos teóricos conceituais (PUC Minas). Experiência e trabalhos publicados na área de Comunicação Organizacional e Relações Públicas. E-mail: mvouguinha@ hotmail.com.

Recebido em: 28.02.2020

Aprovado em: 02.02.2021 